Шугуров M.В.

\title{
К ФИЛОСОФИИ ГЛОБАЛЬНОГО ПАРТНЕРСТВА В ЦЕЛЯХ ГАРМОНИЗАЦИИ МИРОВОГО ИННОВАЦИОННОГО РАЗВИТИЯ
}

\begin{abstract}
Аннотация: Статья посвящена конщептуальному анализу возможностей преодоления глобального инноващионного разрыва через усилия государств, международных организаций и частного сектора по формированию специального направления международного сотрудничества. Инновачионное развитие в мировом масштабе характеризуется как двуединство конкурениии и сотрудничества.Большое внимание уделяется характеристике глобального инновационного прорыва как конвергенции уровней национального инновационного развития. В этом контексте предлагается философия использования инноваций на справедливой и равной основе в глобальном масштабе. Автор сосредотачивается на экспликации идеи опережающего инновационного развития, определяющей стратегию инновационной политики целого ряда государств. В статье затрагиваются новые аспекты взаимоотношений развитых и развивающихся государств, детерминированные глобальной инновационной парадигмой. Помимо этого предлагается связать гармонизацию инновационного развития с идеей "нового мирового экономического порядка" и достижением Целей развития тысячелетия. На основе анализа существующих моделей содействия в инновационном развитии автор приходит к выводу о необходимости формирования новой культуры взаимодействия между различными государствами в сфере содействия наращивания инноващионного потенциала. Формулируется идея глобального управления инновационным развитием, которая в обязательном порядке должна опираться на идею сотрудничества и доверия. Основной вывод, к которому приходит автор статьи заключается в том, что только режим доверия и партнерства способен согласовать инновационное развитие с форматом устойчивого развития в планетарном масштабе.

Review: The article is devoted to the conceptual analyzes of possibilities to overcome the global innovation gap through efforts undertaken by the countries, international organizations and a private sector for formation of special targets in international cooperation. On a global scale, innovative development is described as a unity of competence and cooperation. Much attention is paid at describing the global innovation gap as a convergence of different levels of national innovative development. In this regard, the author offers a philosophy of global use of innovations based on justice and equality principles. The author of the article focuses on explication of the idea of priority innovative development which defines the strategy of innovation policy in a whole number of countries. The author of the article also touches upon new aspects of relations between developed and developing countries with reference to global innovation paradigm. In addition, the author suggests to relate harmonization of innovative development and the new world economic order and achievement of the Millennium Development Goals. By analyzing existing models of innovative development cooperation, the author concludes that it is necessary to establish a new culture of cooperation between countries in the sphere of building up innovative capacity. The author also offers a concept of global management of innovative development based on the principles of cooperation and trust. The main conclusion made by the author of the article is that only the relations built on trust and partnership can coordinate global innovative and sustainable developments.
\end{abstract}

Ключевые слова: инновачионная парадигма, глобализация, инноваџионный разрыв, инновационная политика, международные отношения, международное сотрудничество, инновачионный прорыв, устойчивое развитие, миропорядок, доверие

Keywords: innovation paradigm, globalization, innovation gap, innovation policy, international relations, international cooperation, innovation breakthrough, sustainable development, world order, trust.

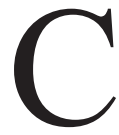

овременный мир переживает серьезные кризисные процессы, связанные с широкими масштабами кризиса легитимности и уменьшением эффективности многосторонних действий. В настоящее время много говорится о формировании разных систем глобального управления, например, перехода к устойчивому развитию, распределения мировых природных ресурсов и т.д. В основе любой 


\section{Политика и общество $7(103) \cdot 2013$}

системы глобального управления находятся институты - международные органы и организации, которые должны располагать наиболее перспективными подходами, как к пониманию необходимости осуществляемого на их основе международного сотрудничества, его проблем и направлений их разрешения, так конкретных механизмов координации взаимодействия.

В связи с тем, что одним из перспективных векторов международного сотрудничества выступает инновационно-технологическое сотрудничество, в условиях глобализации с ним связываются надежды на решение проблем, порожденных самой же глобализацией. При этом следует учитывать, что данное сотрудничество в свою очередь представляет достаточно проблемное поле, требующее коллективных усилий по разрешению возникающих здесь сложностей, связанных с издержками функционирования одностороннего «мирового технологического порядка». Поэтому важнейшим направлением мирового инновационнотехнологического развития и сотрудничества является не только наращивание научного, технологического и инновационного потенциала, но и сокращение инновационного разрыва, представляющего собой существенные диспропорции в уровне инновационного развития стран и отдельных регионов ${ }^{1}$.

Важнейшим механизмом преодоления глобальных инновационно-технологических неравномерностей, привносящих напряженность во взаимодействие государств и народов, является формирование эффективного глобального партнерства как системы оформленных и скоординированных действий в данной сфере. Таким образом, глобальное инновационное развитие не только конституируется как неизбежное пространство конкуренции, но и как сфера интернационализации, интеграции и сотрудничества в деле производства, передачи и диффузии инноваций в целях их всеобщего использования на равной и справедливой основе.

В современной экономической науке высказывается тезис о том, что «перспективы развития мировой экономики будут зависеть от темпов разработки новшеств и скорости диффузии новых технологий, формирования новых отраслей» ${ }^{2}$. Однако позитив-

\footnotetext{
${ }^{1}$ Более подробно см.: Шугуров М.В. Инновационное развитие в современном мире: природа и контуры диспропорций // Политика и общество. 2012 № 8. С. 37 - 52.

${ }^{2}$ Глобальная трансформация инновационных систем / Отв. ред. чл.-корр. РАН Н.И. Иванова. М., 2010. С. 6.
}

ный характер таких перспектив в глобальном масштабе станет возможен лишь в случае сокращения глобального инновационного разрыва. Это требует формирования и осуществления соответствующей инновационной политики на глобальном уровне. Представляется, что в отличие от национальной инновационной политики, достаточно хорошо изученной в аналитической литературе ${ }^{3}$, глобальная инновационная политика только начинает входить в пространство концептуального анализа. Поэтому можно отметить, что в настоящее время наиболее актуальным ее вектором выступает выработка и проведение совместных действий, имеющих форму сотрудничества и партнерства.

Как видится, философия глобального партнерства - это его дух и устремления - должна исходить из общих коренных интересов всего мирового сообщества, а также из совпадающей системы ценностных ориентаций - достойного уровня жизни населения во всех регионах мира, императивного характера повсеместного использования инноваций, уважения и соблюдения права человека и народов на развитие. Только на этом пути возможна реализация проекта «глобального инновационного общества», заявленного на саммите «Большой восьмерки» еще в 2006 году (СанктПетербург). В п. 5 Итогового документа «Образование для инновационных обществ» подчеркивалась значимость общего видения инновационного общества, находящегося в основании совместных и скоординированных действий.

Основной интенцией глобальное партнерства должно стать разрешение основного противоречия глобализации, выступающего существенным барьером для реализации ее более оптимального сценария. Это противоречие, с одной стороны, между возможностями, открываемыми небывалыми доселе масштабами генерирования, трансфера и диффузии инноваций как ресурса ускоренного развития, а с другой - ограниченными возможностями использования инноваций в тех или иных регионах мира. Альтернативой такой модели является устойчивое (сбалансированное) и безопасное инновационное развитие, насколько это вообще возможно для инновационной эволюции, имеющей неопределенный характер.

\footnotetext{
${ }^{3}$ Инновационная политика. Россия и мир: 2002 - 2010 / Под общ. ред. Н.И. Ивановой и В.В. Иванова. М., 2011; Гончаренко Л.П., Арутюнов Ю.А. Инновационная политика. М., 2009.
} 
В целом формирование программы глобального инновационного прорыва еще впереди. Но осознание потребности в том, что инновации должны быть использованы совместно, на благо всех, уже сформировалось и уходит своими корнями, в том числе, в международно-правовые положения о необходимости развития науки и техники на благо человечества и в интересах мира.

Преодоление инновационного разрыва осуществляется индивидуальными и коллективными усилиями государств. При этом нельзя умалять ни первые, ни вторые. Коллективные усилия возможны лишь в формате преодоления «инновационного эгоизма» развитых стран, шествующих по олимпу инновационной монополии и содействующих закрепления статуса остального мира в качестве территории, из которой экспортируется сырье и на которой размещаются грязные производства. Отказ от эгоизма (сконцентрированности исключительно на своем инновационном развитии), но, разумеется, не от своих законных интересов, должен быть характерен и для новых инновационных держав, клуб которых в настоящее время претерпевает расширение.

В современном мире есть основания для усмотрения воспроизведения тенденции научно-технологического доминирования Запада, а ныне - Севера. Это находит свое преломление в его инновационном доминировании, конкретизирующем некогда существовавший «сциентистский расизм» ${ }^{4}$. Вместе тем ввиду инновационных прорывов незападных цивилизаций инновационное доминирование существенно ограничено в своем сползании к «инновационному расизму».

В современных условиях отсутствие интеграции в инновационное развитие коррелятивна инновационной «сдавленности» развивающихся стран и отсутствию у них позитивной перспективы. Поэтому достаточно давно поднятая проблема нового экономического порядка предполагает сегодня такие аспекты, как справедливый инновационный и технологический порядок, установление которого требует особых мер и программ сотрудничества. Инновационный ресурс, в случае обеспечения доступа к нему развивающихся стран, мог бы содействовать решению тех проблем, на которые нацеливают Цели развития тысячелетия (MDGs).

${ }^{4}$ Adas M. Machines as the Measure of Man: Science, Technology, and Ideologies of Western Dominance. Ithaca; London, 1989. P. 403.
Для этого, как представляется, необходимо решить проблему масштабного расширения глобального инновационного сотрудничества, что предполагает выработку определенных инструментов. Только в этом случае можно стать свидетелем не локальных инновационных прорывов, а глобального инновационного прорыва в качестве конвергенции уровней и темпов инновационного развития, что может стать способом преодоления различных «пропастей», особенно в доходах на душу населения и человеческого капитала.

С методологической точки зрения глобальный инновационный прорыв является альтернативой существующего пока неравномерного и несбалансированного инновационного развития глобального мира. Несмотря на отдельные прорывы, сценарий выборочного инновационного развития в целом можно назвать инериионнылм. Модель глобального инновационного прорыва складывается из локальных прорывов, но не на основании логики суммы, а по логике всеобъемлющего синергетического эффекта отдельных достижений. Вполне понятно, что условием такого эффекта может стать некая скоординированность действий по выработке инновационных способов сбалансированного глобального инновационного прорыва - инновационной политики выравнивания инновационного развития через инновационное сочетание конкуренции и сотрудничества.

По всей видимости, в условиях инноватизации глобализации именно через ускоренное создание нового глобального инновационного порядка, основанного на межцивилизационном партнерстве, могут возникнуть условия для перехода к модели справедливой глобализации. Глобальный инновационный прорыв станет контекстом зримого сокращения технологического и экономического разрывов со всеми вытекающими отсюда последствиями.

Из того, что НТП сегодня ускоряется, образуя инновационные и технологические разрывы, означающие неравномерное распределение благ между континентами, государствами и регионами, еще не означает, что прогресс, в принципе, возможет только там, где он уже заметным образом продвинулся вперед и происходит наиболее быстро. Неопределенность инновационного процесса может предполагать неожиданные прорывы там, где их никто не предполагал. Инновационность, и в этом суть ее парадигмы, характеризуется неожиданностью и допускает возможность скачка с периферии в авангард, что означает опережение элиты инновационного развития. 


\section{Политика и общество $7(103) \cdot 2013$}

Сегодня возможность таких скачков в инновационном развитии связывается не с освоением нового технологического уклада (ТУ), на который переходит мировая элита в сфере инноваций и технологий, а с опережающим развитием того ТУ, который является наиболее уделенным во времени. К более удаленным технологиям, которые могут находиться в основе нового поколения инноваций, относят, например нанотехнологии. При реализации этого сценария осуществляется новая конфигурация инновационного разрыва, хотя при этом его несбалансированность воспроизводится на новом уровне.

Полная выравненность национальных инновационных систем в их эффективном функционировании вряд ли возможна, но сокращение недопустимых различий крайне желательно и целесообразно. Это наиболее важная, своего рода осевая проблема современности, требующая инновационных инициатив со стороны частного сектора, государств, международных организаций и, разумеется, самих инноваторов. Данные стратегии вполне можно развивать на уже имеющейся основе инновационных прорывов в рамках индивидуальных или коллективных усилий.

В качестве примера индивидуальных прорывов можно привести Израиль и Финляндию, которые буквально за последние десять лет сумели создать инновационную экономику. Этого удалось добиться на основе системного подхода к формированию национальной инновационной системы (НИС) и совершенствованию необходимых финансовых институтов и инструментов. Одним из факторов прорыва в инновационном развитии выступает существенное увеличение финансирования исследований и разработок до 4-4,5 \% ВВП (Китай, Турция, Израиль, ЮАР). Это один из заметных трендов логики инновационного прорыва. Неслучайно в Стратегии ЕС «Европа-2010» ставится задача увеличения объемов инвестиций в R\&D. При этом следует признать, что суммативное увеличение бюджетного, как и частного финансирования разработок не во всех случаях приводит к коммерческому эффекту от реализации инноваций, что требует укрепления всех остальных факторов инновационного развития.

Государства, сумевшие выработать и осуществить эффективную инновационную политику, прорываются на передовые рубежи инновационного развития через самопомощь и вносят вклад в закрытие локальных разрывов в глобальном инновационном ландшафте. Необходимо отметить, что направления сокращения локальных разрывов достаточно диверсифициро- ваны. Сюда может входить практика по усиленному копированию зарубежных технологических новшеств посредством интеллектуального пиратства, чем занимается Китай. Однако сценарий догоняющего сокращения проблематизирует перспективу сравняться с лидерами инновационного развития: копирование продуктов, технологий, организационно-управленческих методов обрекает на постоянное нахождение на одном или двух шагах позади. Поэтому тот же Китай сформулировал ныне в качестве приоритета стратегию опережающего инновационного развития.

В целом стратегия опережающего инновационного развития является наиболее перспективным решением по выходу из состояния инновицонно-технологического отставания. Суть рассматриваемой стратегии заключается в повышении глобальной конкурентоспособности через создание инноваций, конкурентоспособных в глобальном масштабе, т.е. инноваций глобального значения (так называемых эпохальных инноваций), которые на данное время пока что либо не известны, либо не являются широко распространенными. Одновременно это предполагает позиционирование в качестве аттракторов цепочек глобального инновационного процесса.

Конечно, реализовать такой сценарий способны не все страны. Но впечатляющие примеры таких прорывов все же существуют. В качестве примера можно привести опыт выхода Дании в лидеры ветровой энергетики ${ }^{5}$ В качестве другого примера можно привести «сингапурское чудо», суть которого заключает в успешном генерирование эпохальных инноваций, относящихся к следующему - шестому технологическому укладу. Уже с конца XX века здесь осуществлялась инновационная политика, направленная на переключение с микроэлектроники на разработку и коммерциализацию в глобальном масштабе биотехнологий и фармацевтики. В результате разработанных мер финансового, налогового и антикоррупционного характера на территории Сингапура были привлечены фармацевтические ТНК, которые в размещенных здесь лабораториях и филиалах стали создавать полные инновационные циклы ${ }^{6}$.

Опыт инновационного прорыва Японии, Финляндии, Южной Кореи показывает алгоритм успеха - углубление и повышение эффективности

${ }^{5}$ Abbude L. Haw Denmark Paved the Way to Energy Independence // Wall Street Journal. 2007, April.

${ }^{6}$ Biopolis: Design for Life. Singapore, 2006. 
взаимодействия науки, образования, бизнеса, государства, в результате чего стало возможным достижение синергетического эффекта. Достаточно интересный опыт возникает буквально на глазах во Франции, где инновационный разрыв преодолевается на основе проведения массированной кластерной политики и через мобилизацию усилий всех акторов инновационного процесса в рамках общенационального форума «Генеральные штаты промышленности».

Стратегия инновационного прорыва предполагает выход на передовые рубежи инновационного развития и включение на равных правах в глобальные инновационные процессы. В настоящее время стратегия инновационного прорыва реализуется в Казахстане. Инструментом достижения амбиционных целей (вхождение к 2016 году в клуб государств с высоким уровнем доходов на душу населения) является Программа форсированного индустриальноинновационного развития.

Если иметь в виду Россию, то для нее также наиболее оптимальным является стратегия инновационного прорыва. Понимание необходимости такой стратегии сформировалось практически десятилетие назад. Однако масштабный институциональный механизм встраивания в мировой инновационный процесс не в качестве потребителя технологических и продуктных инноваций, а их генератора, причем на глобальном уровне, стал формироваться буквально только сейчас и представлен, например, Центром коммерциализации технологий «Сколково».

Как мы уже говорили, сокращение инновационного разрывав в глобальном масштабе требует глобального партнерства со стороны государств, международных организаций и ТНК. Данное партнерство должно исходить из осознания насущного характера сокращения такого разрыва, основываться на соответствующей стратегии и осуществляться в рамках высокой глобальной инновационной культуры, включающей в себя, в том числе, диалог по проблемам глобального инновационного развития. Стратегия сокращения инновационного разрыва должна быть инновационной и должна представлять собой основу для согласованной и инновационной политики помощи и содействия в инновационном развитии.

Инновационность выступает сегодня не только парадигмой развития, но и общей парадигмой помощи в развитии. Достаточно ярко это прослеживается в поиске инновационных механизмов финансиро- вания развития, инициированного ООН. По своему характеру методы сокращения инновационных диспропорций в глобальном масштабе являются ничем иным, как способами содействия инновационному развитию в формате «государство - государство», «международная организация - государство». Данные способы направлены на активизацию факторов инновационного развития через проектное финансирование, консультационные услуги и техпомощь в создании эффективной инновационной системы и инфраструктуры, особенно в деле оптимизации взаимодействия в рамках Тройной спирали (государство - частный сектор - генераторы инноваций). Как от государств-партнеров, так и от международных организаций могут исходить и на практике реально исходят предложения по укреплению взаимодействия данных элементов и повышении культуры диалога и партнерства между ними.

Реальность сохраняющегося, в чем-то уменьшающегося (в отношении ИКТ), а в чем-то увеличивающегося (в отношении нанотехнологий) инновационного разрыва означает, что степень реализации инновационной парадигмы в значительной части регионов современного мира вызывает затруднения. Однако парадигмальный статус инновационности предполагает, что развитие инновационной активности как способа научно-технологического и экономического развития не является некой излишней роскошью и устойчивым приоритетом богатых стран. Этот способ жизненно важен и для бедных стран, которые стремятся к экономическому развитию. Вместе с тем, это способ, надо признать, был «изобретен» и придуман именно в богатых странах и задал основной вектор мирового экономического и научно-технологического развития. С другой стороны, возникает следующий вопрос: если развитый мир задал данную парадигму, то он должен, признавая право развивающегося мира на развитие, оказывать содействие в освоении и реализации данной парадигмы.

В сложившейся геоинновационной ситуации право народов и государств на инновационное развитие осуществляется выборочно. Большая часть государств не в состоянии самостоятельно превозмочь различные барьеры инновационного развития, что приводит к неосуществленности права на развитие в целом. Никакое увеличение импорта инноваций не в состоянии осуществить переход к приемлемым инновационным различиям, ибо в этом случае требуется системная помощь и содействие в сфере инновационного развития. 


\section{Политика и общество $7(103) \cdot 2013$}

Научно-техническая и технологическая помощь - достаточно изученное явление в мировой экономической мысли. Однако сегодня она становится малоэффективной, если не встраивается в формат содействия в помощи инновационному развитию. Главное направление мировой политики по преодолению инновационного разрыва - это политика в сфере содействия инновационному развитию, проводимая международными организациями. На уровне Группы Всемирного банка, ЮНКТАД, ЮНИДО накоплен определенный опыт по оказанию содействия в деле содействия развитию национальных инновационных систем в развивающихся странах. Заметную роль в выравнивании глобального инновационного ландшафта играет ВОИС, стремящаяся к интеграции развивающихся и наименее развитых страх в глобальном инновационном процессе путем сокращения в разрыве знаний через их активное распространение и обеспечения доступа к ним, не говоря уже о деятельности в сфере правовой охраны и защиты инноваций.

Стремление к оказанию помощи в преодолении инновационного разрыва характерно для ОЭСР, которая осуществляет мониторинг параметров инновационного развития не только своих государств, но и государств, которые в данную организацию не входят. Большое значение имеют обзоры, касающиеся анализа национальных инновационных политик, в которых формулируются рекомендации по их совершенствованию. В частности, в своем Обзоре инновационной политики РФ за 2010 год ОЭСР указала на необходимость повышения внимания поддержки инноваций на крупных, средних и малых предприятиях; необходимости поддержки инноваций на низко-технологичных производствах, на осуществлении большей открытости международному сотрудничеству в сфере исследовании и разработок ${ }^{7}$.

Слабые инновационные системы одновременно означают и слабую интегрированность в глобальную инновационную систему (ГИС) и мировую экономику знаний, что также является препятствием для достижения целей развития. Поэтому инновационный, также как и технологический разрыв, является предметом заботы сообщества развития (development society), который предполагает разработку концептуальных мо-

\footnotetext{
7 Организация экономического сотрудничества и развития подготовила обзор инновационной политики Российской Федерации (30 мая 2011 года) // http://gtmarket.ru/news/ state/2011/05/30/2956 (дата обращения: 4.06.2013).
}

делей и реализацию способов сокращения диспропорций в интенсивности разработки и коммерциализации технологических новшеств.

Вместе с тем, несмотря на повышение ответственности международных организаций, которые сейчас принято рассматривать в качестве институтов глобального и регионального развития главную ответственность за развитие, в том числе национальное и глобальное инновационное развитие, несут, конечно же, государства. Одним из достаточно показательных индикаторов инновационного развития той или иной экономики является наличие государственной инновационной политики, которая стала в последнее время превращаться в самостоятельное явление и включаться в себя научно-технологическую политику. Эффективность данной политики показывает степень осознания публичной властью значимости развития инновационной системы, что находит свое проявление во включении приоритетного развития науки, технологии и инновации (STI) в стратегии развития на национальном уровне. В этой связи хотелось бы заметить, что ответственность государств не исключает ответственности всего мирового сообщества, представленного также транснациональным бизнес-сообществом.

Однако, к сожалению, такая включенность характерна не для всех государств. Эта констатация относится к государствам южнее Сахары, а также государствам арабского мира и некоторых латиноамериканским государствам. То, что инновации не занимают центральное место в национальных стратегиях развития, выглядит анахроничным и говорит о несовременном характере подобных государств. Поэтому не случайно Генеральная Ассамблея ООН призывает включать инновационную и научно-технологическую политику в национальные стратегии развития. Для того, чтобы в мире происходило соревнование и взаимовыгодное сотрудничество инновационных систем и инновационных политик, необходимо, чтобы государства предпринимали усилия для самовключения в инновационное развитие, а также в активное сотрудничество с «сообществом развития».

Перед большинством государств современного мира стоит задача модернизации. В том случае, если модернизация не приводит к повышению уровня инновационной активности, то возникают тупики трансформации. Поэтому модернизация должна предполагать формирование инновационных институтов на национальном уровне через реформы и принятие соответствующего законодательства. Данные 
усилия не могут быть замкнутыми. Осознание государствами, не без влияния со стороны международных организаций того обстоятельства, что они находятся в невыгодном свете с точки зрения новаторских разработок и их коммерциализации, должно стать началом для шагов, в том числе, в сфере международного сотрудничества и развития. Следовательно, инновационная модернизация предполагает активный вектор внешней инновационно-технологической политики в сфере международного научного и инновационно-технологического сотрудничества.

Интенсификация вовлечения в мировой хозяйственный оборот новых технологических разработок, имеющих системное значение для экономики и часто именуемых высокими технологиями, стала отправной точкой для возникновения нового явления на мировом уровне. Отныне традиционное международное научно-техническое сотрудничество уступило место более сложному явлению - международному научному, научно-технологическому и инновационному сотрудничеству. Все большее число государств оказываются вовлеченными в глобализацию, предполагающую приоритетность инновационного и технологического развития. Одновременно с этим особую важность в качестве самостоятельного явления приобретает мировая политика в сфере международного научно-технологического развития и сотрудничества как пространство согласования соответствующих целей и интересов.

Активное формирование сетевого международного инновационного сотрудничества как пространства глобальной инновационной политики предполагает миросистемные характеристики глобального инновационного развития. Смысл глобальной инновационной политики заключается в том, чтобы конституировать глобальное пространство ответственности за устойчивое и сбалансированное инновационное развитие.

Безусловно, инновационный разрыв - это разрыв «между». Но одновременно - это и разрыв «в», а именно - разрыв в ГИС, существование которой подтверждает невозможность изолированного инновационного, равно и технологического развития. Поэтому речь может идти об институционализации глобального инновационно-технологического развития в рамках ГИС, где происходит создание, трансфер и диффузия технологических новаций в мировом масштабе. ГИС оказывает воздействие на развитие политики государств, международных организаций и межгосударственных объединений интеграционного и квазиинтеграционного типа в сфере международного научно-технологического и инновационного сотрудничества. Вместе с тем она выполняет и еще одну функцию. Так, достаточно амбициозные проекты по разработке инновационных технологий предполагают механизмы международного сотрудничества, взаимодействия и интеграция.

Обычно международное сотрудничество в данной сфере понимается как обмен технологическими инновациями. Однако такой обмен просто не может состояться, если у тех или иных стран отсутствует национальная инновационная система. В этом случае инновационный разрыв превращается в самостоятельное явление, структуру. Находясь под ее воздействием, развивающиеся страны не в состоянии использовать технологические разработки, созданные в развитых странах.

В соответствии с подходом, разделяемым международными организациями, уделяющим внимание мониторингу глобального научно-технологического прогресса и его осуществлению, для преодоления технологического разрыва и, соответственно, устойчивого экономического роста недостаточно иметь доступ к технологиям. Если предположить, что даже при удачном стечении финансовых обстоятельств такой доступ будет обеспечен, гарантия того, что они будут «разупакованы» отсутствует. Импорт технологий требует их усвоения (adoption) и адаптации (adaptation), т.е. «доведения». Для этого импортированные технологии должны оказаться в атмосфере национальной инновационной системы в той ее части, которая занимается этими видами работ. В частности, для решения глобальной проблемы голода развивающиеся страны нуждаются в биотехнологиях. Однако данные технологии, поставляемые в готовом виде, должны быть усвоены и освоены, что предполагает задействование инновационно-технологического потенциала.

Сбалансированный инновационный обмен предполагает оптимальное сочетание экспорта и импорта инноваций. Большинство же развивающихся стран не только не экспортируют инновации в силу отсутствия НИС, но и будучи ориентированными на привлечение зарубежных инноваций, испытывают затруднения в их усвоении и адаптации. Невозможность не только производства, но и усвоения зарубежных инноваций является одним из индикаторов инновационного разрыва, причем его наиболее тяжелой формы. 


\section{Политика и общество 7 (103) • 2013}

В том случае, если государства занимаются усвоением или адаптацией технологий, то их инновационная система находится на самой начальной стадии инновационного развития. Так, на стадии усвоения находятся Боливия, Гватемала, Гондурас. На стадии адаптации - Колумбия, Бразилия, а на стадии создания - Чили, Мексика. Следовательно, помощь в инновационном развитии в принципе должна исходить из реальных обстоятельств каждой страны и ориентироваться не только на экспорт инноваций, но и на содействие государствам в становлении благоприятного инновационного климата.

Центральное значение для содействия технологическому и инновационному развитию выступает содействие в развитии инновационных систем, которые не только бы адаптировали импортные технологии и инновации, но и производили бы собственные. Это наиболее трудная часть помощи в инновационно-технологическом развитии. Исходя из соображений конкурентного характера, помощь может быть нацелена не на полную передачу опыта, а на частичную. При этом в помощи могут быть и отвлекающие маневры стремление донора тиражировать инновационные решения по организации инновационного процесса при заведомом их «износе», что является недостаточно очевидным для реципиента. В этом случае организационно-управленческие инновации являются псевдоили даже антиинновационными. Например, сегодня на смену некогда инновационной модели Кремниевой долины приходят другие способы организации инновационного процесса, например, круглосуточный инновационный бизнес, определяемый алгоритмом сокращения инновационного цикла. Поэтому заимствовать способы организации инновационного процесса, полностью аналогичные Кремниевой долине, сегодня не достаточно осмотрительно. Кремниевая долина - достаточно давняя инновационная модель, которая оказала некогда революционизирующее воздействие на общество и его экономику ${ }^{8}$.

В настоящее время некогда эффективные инновационные модели становятся бременем и приводят к ловушке лидерства: лидер превращается в заложника своих инновационных моделей, его развитие тормозиться, что открывает возможность для инновационного скачка конкурентов, начиная от фирм и заканчивая государствами. Однако это не

${ }^{8}$ См.: Рюгемер В. Новая техника - старое общество: Кремниевая долина. М., 1988. исключает возможности улучшающих инноваций. Так, в 60 - 70-ее гг. XX века Япония переняла опыт американских технопарков, но адаптировала их в форме технополисов 9 .

Кстати говоря, в глобальных условиях имеет место не только конкуренция инноваций, но и конкуренция инноваций в сфере организации и управления инновационным процессом. Такие ноу-хау являются стержнем конкуренции и не могут быть полностью рассекречены. Поэтому даже в условиях сотрудничества элементы конкуренции будут оставаться на межфирменном и межстрановом уровнях, требуя проведения стратегически и тактически выверенной инновационной дипломатии.

И последнее, инновационная дипломатия, как и инновационное развитие, обладает очень важным аспектом - информационным. Глобализация инновационного развития, характеризуемая глобальным распространением инноваций и их обменом, предполагает всестороннюю интеграцию в процессе их создания через подключения к соответствующим информационным ресурсам. Поэтому важнейшим направлением мирополитических усилий в сфере инновационного глобального партнерства должно стать создание надлежащего мирового информационного порядка как условия равномерного инновационного развития, позволяющего обмениваться опытом по генерированию и использованию инноваций.

\section{Библиография:}

1. Глобальная трансформация инновационных систем / Отв. ред. чл.-корр. РАН Н.И. Иванова. М.: ИМЭ РАН. 2010.

2. Гончаренко Л.П., Арутюнов Ю.А. Инновационная политика. М.: Кнорус, 2009.

3. Инновационная политика. Россия и мир: 2002 2010 / Под общ. ред. Н.И. Ивановой и В.В. Иванова. М.: Наука, 2011.

4. Ожиганов Э.Н. Политика инновационного развития. Глобальная конкуренция и стратегические перспективы России. M.: URSS, 2012.

5. Рюгемер В. Новая техника - старое общество: Кремниевая долина. М.: Политиздат, 1988.

6. Тацуно Ш. Стратегия - технополисы. М.: Прогресс, 1989.

\footnotetext{
${ }^{9}$ См.: Тацуно Ш. Стратегия - технополисы. М., 1989.
} 
7. Шугуров М.В. Инновационное развитие в современном мире: природа и контуры диспропорций // Политика и общество. 2012. №

8. Abbude L. Haw Denmark Paved the Way to Energy Independence // Wall Street Journal. 2007, April.

9. Adas M. Machines as the Measure of Man: Science, Technology, and Ideologies of Western Dominance. Ithaca, London: Cornell University Press, 1989.

10. Biopolis: Design for Life. Singapore: JTC Corporation, 2006.

\section{References (transliteration):}

1. Global'naya transformaciya innovacionnyh sistem / Otv. red. chl.-korr. RAN N.I. Ivanova. M.: IME RAN. 2010.

2. Goncharenko L.P., Arutyunov Yu.A. Innovacionnaya politika. M.: Knorus, 2009.
3. Innovacionnaya politika. Rossiya i mir: 2002 - 2010 / Pod obsch. red. N.I. Ivanovoy i V.V. Ivanova. M.: Nauka, 2011.

4. Ozhiganov E.N. Politika innovacionnogo razvitiya. Global'naya konkurenciya i strategicheskie perspektivy Rossii. M.: URSS, 2012.

5. Ryugemer V. Novaya tehnika - staroe obschestvo: Kremnievaya dolina. M.: Politizdat, 1988.

6. Tacuno Sh. Strategiya - tehnopolisy. M.: Progress, 1989.

7. Shugurov M.V. Innovacionnoe razvitie v sovremennom mire: priroda i kontury disproporciy // Politika i obschestvo. 2012. №

8. Abbude L. Haw Denmark Paved the Way to Energy Independence // Wall Street Journal. 2007, April.

9. Adas M. Machines as the Measure of Man: Science, Technology, and Ideologies of Western Dominance. Ithaca, London: Cornell University Press, 1989.

10. Biopolis: Design for Life. Singapore: JTC Corporation, 2006. 